\title{
Carbon management planning in UK universities: A journey to low carbon built environment
}

\author{
Muhammad Usman Mazhar ${ }^{1}$ \\ Department of Management, Nottingham Business School, Burton Street, Nottingham, NG1 \\ 4BU, United Kingdom \\ ${ }^{1}$ muhammadusman.mazhar@ntu.ac.uk
}

\author{
Richard Bull ${ }^{2}$, Mark Lemon ${ }^{3}$ \\ Institute of Energy and Sustainable Development, De Montfort University, \\ The Gateway, Leicester, LE1 9BH, United Kingdom \\ 2 rbull@dmu.ac.uk ${ }^{3}$ mlemon@dmu.ac.uk \\ Saad Bin Saleem Ahmad ${ }^{4}$ \\ Department of Civil and Environmental Engineering, \\ Norwegian University of Sciences and Technology, Trondheim, Norway \\ 4saad.ahmad@ntnu.no
}

\begin{abstract}
Climate change and increase in carbon emissions are one of the biggest challenges for the modern world. Organisations are facing increasing pressure from governments and stakeholders to reduce carbon emissions. The Higher Education (HE) sector has a huge environmental, social and economic impact. In 2012-13, Higher Education Institutions (HEIs) consumed 7.9 billion $\mathrm{kWh}$ of energy and emitted 2.3 million tonnes of carbon emissions, which strengthens the role of universities in implementing carbon management for a low carbon built environment. The HE sector is not exempt from implementing carbon management strategies and responded to the UK government's Climate Change Act by developing its own targets in England, which are in line with the national targets $-80 \%$ reduction by 2050 and $34 \%$ by 2020 from the 1990 baseline. This indicates the scale of the challenge to implement carbon management through effective planning procedures.
\end{abstract}

The aim of this paper is to explore the key elements of the carbon management planning process in UK universities and identify potential areas of improvements. This exploratory study adopted a qualitative and inductive research approach. The data were collected through the content analysis of eighteen universities' carbon management plans (CMPs). The study found that key elements of carbon management planning are; senior management leadership, carbon footprinting, carbon reduction targets, stakeholder engagement, funding \& resources, governance and evaluation \& reporting. Universities have shown policy commitment and developed CMPs for implementation, but the performance of universities varies significantly. There is also a disconnect between planning and delivery. Findings of this research show that CMPs can be valuable tools to assist universities in their carbon management journey. However, weaknesses are identified in the current design of CMPs, for example, overly focusing on the technical issues of carbon management (to the detriment of socio-technical factors), unsupportive of stakeholder engagement, not aligned with core policies and strategies and being static documents. CMPs are not comprehensive with regards to the operational boundary of carbon emissions and need standard approach for measuring, targeting and reporting. This study will be useful to academics and practitioners aiming to improve carbon management planning in universities and other organisations. 


\section{Keywords}

Carbon management, planning, universities, low carbon built environment.

\section{Introduction}

The mounting evidence for climate change is one of the most important issues for organisations due to increasing carbon emissions. Organisations have started to consider 'carbon 'into their strategic positioning (Lee 2012). Against this background, proactive actions are required by all of the organisations to plan and implement carbon management strategies. The public sector recognises the benefits of carbon management and sees the short-term as well as long-term advantages of its implementation (The Carbon Trust 2012). Higher Education Institutions (HEIs) including universities have recognised themselves that they are well placed to take on a leadership role in implementing carbon management (KleinBanai and Theis 2013). In 2012-13, HEIs consumed 7.9 billion kWh of energy and produced 2.3 million tonnes of emissions (Higher Education Statistics Agency 2014). This indicates the scale of the problem in universities. The HE sector emits these carbon emissions due to the nature of its operational business activities. The increasing carbon emissions in universities need to be managed through effective planning process.

Carbon management has been high on global and the UK policy landscape. In 2006, the Stern Review indicated that a $25 \%$ carbon emissions reduction below current levels is required to stabilise global $\mathrm{CO}_{2}$ emissions at levels that will not have harmful impacts and states that the cost of not acting on climate change is greater than the cost of acting now (Stern 2006). In response to global and the European climate change policies, the UK became the first country to introduce the Climate Change Act 2008 aiming for $80 \%$ carbon emissions reduction by 2050 and $34 \%$ by 2020 as compared to a 1990 baseline (Her Majesty's Stationery Office 2008). The Higher Education Funding Council for England (HEFCE) adopted the same targets, which against a 2005 baseline are equivalent to a reduction of $43 \%$ by 2020 and $83 \%$ by 2050 (HEFCE 2010b). Universities in the UK had to develop CMPs to respond to their funding bodies such as universities in England developed institutional CMPs for policy compliance on the advice of HEFCE. At that time, the success in meeting the targets in CMPs was a contributory factor in future capital funding allocations for universities (HEFCE 2008). This was a strong policy driver to move universities forward with regards to carbon management and get senior management leadership on board.

CMPs present an official position of universities on how they are planning to implement carbon management strategies to meet their targets. Brite Green (2015) found that the majority of the English universities are further behind from achieving their 2020 carbon reduction target. Therefore, universities need to take a strategic approach to develop and manage CMPs and address the necessary gaps. This research aims to explore the key elements of the carbon management planning process in UK universities and identify potential areas of improvements. This helps assess universities' level of compliance and adoption of national and HE sector carbon reduction policies and strategies by developing CMPs which is a major carbon management tool. The literature is reviewed around carbon management planning in organisations and universities. Then the research methodology is discussed following the data analysis and results. Finally, the paper includes a discussion of the main research findings with conclusions and recommendations presented.

\section{Organisations and Carbon Management Planning}

Carbon management has business case for organisations (Busch and Shrivastava 2011) and it has been slowly moving up the strategic management agenda. Organisations have started to 
understand the need to implement carbon management strategies (Carbon Disclosure Project 2010). There is a relationship between an organisation's carbon management strategy, the sector it operates in and the size of the organisation (Lee 2012). Research into the strategic response to climate change in public and private sector organisations found that carbon management was dependent upon how those organisations 'thought' about carbon emissions (Bebbington and Barter 2011). Frameworks underpinning corporate climate change strategies are developed to reduce carbon emissions in energy intensive companies within the manufacturing and process industries (Kolk and Pinkse 2004). Some previous studies are focused on organisations' efforts to reduce emissions from the production processes and their participation in carbon emissions trading systems. Some of the studies have stressed the need to focus on improving the product and supply chain measures (e.g. Weinhofer and Hoffmann 2010; Hoffman 2007). Cadez and Czerny (2016) explore corporate climate change strategies of carbon-intensive firms to identify configurations of firms pursuing similar strategies and appraise the relationships between nineteen carbon reduction practices and their underlying strategies. The public sector has an opportunity to lead by example in carbon management and influence the private sector organisations (Wehrmeyer et al. 2009). Ball et al. (2009) recommend considering research into 'carbon neutrality' within public sector organisations, as there has not yet been any analysis on how these organisations address emissions. There is a considerable grey literature on public sector carbon management strategies, focussed on higher education, local authorities and National Health Services (NHS) trusts. This suggests that, despite much good practice (The Carbon Trust 2013) proactive actions are required by public sector organisations to reduce carbon emissions.

Higher Education (HE) sector has significant potential to play a key role in supporting the transition to a low carbon economy (Davies and Dunk 2015; Mazhar et al. 2014). The UK HE sector is significant in terms of population, economic contribution and societal influence and is an important sector for implementing carbon management (Robinson et al 2017). Universities are increasingly reporting their carbon emissions as part of their sustainability performance measurement (Klein-Banai and Theis 2013). Much of the focus on carbon emissions reductions and sustainability strategies in universities has been on the energy consumption of buildings; this is largely because they are major contributors to an institution's carbon emissions and they are usually under their direct control (Klein-Banai and Theis 2013). HE institutions should consider how a carbon management strategy will fit into the wider context of their business operations, integrates with existing policies and strategies and can contribute to the delivery of regulatory obligations (HEFCE 2010a). However, the case of HEIs' energy and carbon emissions reduction is considered more complex than other organisations due to the heterogeneity of the sector (Altan 2010). This is due to the fact that many universities have complex built environment, different stakeholders and competing core business priorities in a rapidly changing HE environment.

There is a lack of academic research on issues around carbon management in universities (Robinson et al. 2015; Mazhar et al. 2012, 2014). Much of the existing literature and related research is focused on wider sustainability or green issues rather than planning approaches. Wittneben et al. (2009) states that the theoretical developments in organisational studies and corporate management practices for climate change mitigation have been obsolete. There is literature available in the form of CMPs and HEFCE strategy documents. The focus on research into carbon management planning and its main elements remains limited. Robinson et al. (2015) provided a reality check on carbon management in universities with a focus on English Russell Group universities. This is one of few carbon management studies that has looked into existing CMPs. Robinson et al. (2015) found that current CMPs are not a good indicator of future performance and the HE sector in England has underestimated the 
challenge of carbon management. Therefore, it is of vital importance to study universities' carbon management planning approaches and identify areas of improvement.

\section{Research Methodology}

The study adopted a qualitative and inductive research approach to produce insights into universities' carbon management planning approaches. The data were collected through the content analysis of eighteen UK universities' carbon management plans (CMPs) and strategies. Most of the CMPs were publicly available on university websites due to the HEFCE requirements. Carbon management plans and strategies were chosen for the analysis, as this is the only document that addresses the issue of carbon emissions in universities. The rationale is that it may be difficult to access university management to gain comprehensive insights into carbon management planning process. Therefore, carbon management strategies and plans were used to indicate the perspectives and approaches of different universities. The sample of 18 universities is representative of different types of universities across the UK based on the foundation year (pre-1992 and post-1992). While these universities have other carbon related strategies and policies such as sustainability strategies, travel plans, energy policies and procurement policies, detailed analysis of these documents falls outside the scope of this study. Out of the total eighteen CMPs, sixteen were available on websites. There were two universities that do not have CMPs publicly available on the website. One of them has put a summary of the CMP and the other has placed it on the corporate website, but it is only available on staff web pages. Table 1 presents the names of the eighteen universities with the titles of their carbon management documents. Two universities have given different names to documents for their own branding.

Table 1: Carbon management documents analysed for the study

\begin{tabular}{|l|l|l|l|}
\hline No. & Name of the University & Name of the Document & Year \\
\hline 1 & De Montfort University & Carbon Management Plan & 2011 \\
\hline 2 & University of Leicester & Strategy and Implementation Plan & 2007 \\
\hline 3 & Loughborough University & Carbon Management Plan & 2010 \\
\hline 4 & Nottingham Trent University & Strategy and Implementation Plan & 2008 \\
\hline 5 & University of Derby & Carbon Management Plan & 2009 \\
\hline 6 & The University of Northampton & Carbon Management Plan & 2011 \\
\hline 7 & University of East Anglia & Carbon Reduction Plan & 2012 \\
\hline 8 & University of Cambridge & Carbon Management Plan & 2010 \\
\hline 9 & Leeds Beckett University & Carbon Management Strategy & 2012 \\
\hline 10 & University of Lincoln & Carbon Management Plan & 2011 \\
\hline 11 & University of Nottingham & Carbon Management Plan & 2010 \\
\hline 12 & University of Birmingham & Carbon Management Implementation Plan & 2010 \\
\hline 13 & University of Bradford & Ecoversity - One Planet Strategy & 2011 \\
\hline 14 & The University of Edinburgh & Climate Action Plan & 2010 \\
\hline 15 & Heriot-Watt University & Carbon Management Plan & 2009 \\
\hline 16 & Cardiff University & Carbon Management Plan & 2013 \\
\hline
\end{tabular}




\begin{tabular}{|l|l|l|l|}
\hline 17 & Aberystwyth University & Implementation Plan & 2007 \\
\hline 18 & Queen's University Belfast & Carbon Management Plan & 2013 \\
\hline
\end{tabular}

Themes drawn from the literature were used to underpin a systematic analysis of the CMPs which were then analysed. Additional themes and sub-themes also emerged and are discussed in the ensuing paper. The qualitative data analysis software NVivo 10 was used for the thematic analysis. All of the CMPs were systematically reviewed to develop these themes, as presented in Figure 1. The data were then coded to produce findings. The themes and subthemes were recorded based on the frequency of their occurrence and their usefulness for the carbon management process.

\section{Analysis and Results}

Figure 1 presents the key elements of carbon management planning drawn out during the content analysis of CMPs of universities.

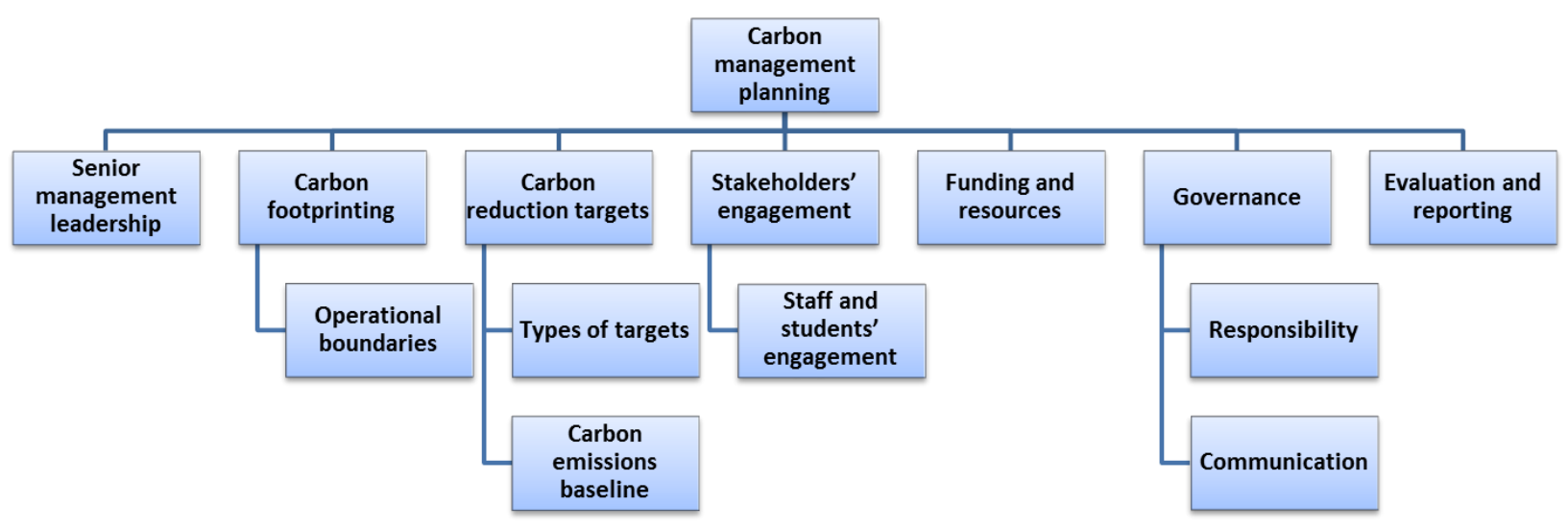

Figure 1: Key elements of carbon management planning

\section{Senior management leadership}

Senior management leadership is the starting point for the carbon management planning process in universities. This theme explores the role of senior management leadership and the extent to which senior management is engaged in carbon management. The carbon management plans (CMPs) of eight, out of the eighteen, universities, have mentioned senior management commitment and their increasing role in carbon management. All of the CMPs officially get signed off by one of the members of senior management team. However, the content analysis suggests that CMPs do not provide evidence for the level of their true engagement, as plan/strategy and implementation may differ. The Nottingham Trent University's Strategy and Implementation Plan describes the importance of senior management support: 
"In order to achieve the greatest possible success, it is essential to have visible top level support for the Carbon Management Programme. This top level support will in turn open up avenues such that the programme can filter through each level of the organisation and as such enable Nottingham Trent University to achieve and exceed its carbon reduction targets as identified in the Carbon Trust Higher Education Carbon Management Programme and the University's Strategic Plan." [Nottingham Trent University Strategy and Implementation Plan, p.59]

Due to the importance of senior management leadership, five out of the eighteen universities are trying to ensure the involvement of senior management. Only three universities mentioned in CMPs that their senior management have already bought into the carbon management process, which suggests a lack of senior management leadership in majority of the universities in reality. The analysis indicates that universities have awareness and an agreement on the role of senior management leadership, but they have not secured their full engagement yet. However, CMPs do not clearly mention a lack of senior management leadership and do not develop strategies or action plans to achieve their engagement. The CMP of the University of Lincoln states the role of senior management leadership for embedding carbon management in the university:

"Carbon management will be led by senior management and will be embedded across the institution through the alignment of policies, management practices and procedures in support of the low carbon vision." [University of Lincoln Carbon Management Plan, p. 8]

In contrast, seventeen out of the eighteen universities' CMPs have a 'foreword' from either a member of senior management team or Vice Chancellor (VC) with the signature to demonstrate that carbon management is backed up by senior leadership. The sign-off does not provide evidence for the real commitment and engagement of senior management, but universities have started to at least consider it in strategic management agenda, if not implement effectively. The University of Leicester's Environment Action Programme (ULeap) supports this:

"The Higher Education Carbon Management Programme (HECM) has helped to bring environmental issues to the top of the University's agenda." [University of Leicester Environment Action Programme (ULeap), P. 7]

Senior management leadership can potentially lead to carbon management being embedded in corporate strategy of the university with a clear strategic vision and support for implementation.

\section{Carbon footprinting}

Carbon footprinting is the measurement of carbon emissions from an organisation's business operations. The content analysis found that carbon emissions measurement is an important element of the carbon management process. The majority of the universities have done carbon footprinting or in the process of doing so. The measurement of carbon emissions is the first step to start managing and reducing emissions.

"Calculating an emissions baseline is the first step in enabling the university to quantify its carbon footprint and to gain a better understanding of its overall carbon contribution." [Loughborough University Carbon Management Plan, p. 15]

Universities are using different methods for carbon footprinting and there is no specific international standard for HE carbon footprinting. HEFCE provided guidelines to measure carbon emissions and many universities have followed that approach. There are other 
internationally recognised carbon footprinting guidelines published by the Global Reporting Initiative (GRI), UK government's Department for Environment, Food and Rural Affairs (DEFRA), the Greenhouse Gas Protocol and the International Standardisation Organisation (ISO).

\section{Operational boundaries}

It is the boundary according to which universities are measuring and managing carbon emissions. Majority of the universities have measured scope 1 and scope 2 emissions. The World Resources Institute (WRI) and World Business Council for Sustainable Development (WBCSD) classified scope 1 as direct emissions that occur from sources owned or controlled by the organisation and scope 2 accounts for emissions from the generation of purchased electricity. Scope 3 is all other indirect emissions that arise as a consequence of various organisational activities, but occur from sources not owned or controlled by the organisation (WRI \& WBCSD 2004). Nine out of the eighteen universities (50\%) have measured scope 1 and 2 emissions as reflected in their CMPs. Therefore, carbon emissions related to energy consumption in buildings and universities' own transport fleet is planned in almost all of the CMPs as universities have control over these emissions. Eight universities have measured scope 1 and 2 with 'selected parts of scope 3 emissions' and only one university has measured complete carbon footprint based on scope 1,2 and 3. The selected parts of scope 3 emissions chosen by eight universities are related to waste and water. Out of these, three universities have calculated emissions associated with staff and student commuting and business travel. Two universities have measured emissions associated with procurement and supply chain. There is no consistent approach as far as scope 3 measurement is concerned. CMPs indicate that majority of the universities have not measured scope 3 and hence, they have not set scope 3 targets. The emissions related to procurement and supply chain, international student travel, business travel and staff and student commuting are overlooked. Many universities are planning to measure and target scope 3 emissions. However, universities have strategies to address various streams of scope 3 carbon emissions.

"Initially scope 1 and scope 2 emissions will be included within the carbon management plan, however moving forward scope 3 emissions will need to be measured and incorporated within the plan." [Loughborough University Carbon Management Plan, p. 18]

HEFCE proposed that universities should commit to scope 3 carbon management with the intention of measuring emissions and setting targets. The majority of the universities (fifteen out of the eighteen) are planning to include scope 3 in their CMPs. Some of the universities have already made estimates of scope 3, but have not developed the reduction targets with accurate carbon footprtint and some are about to set the targets. The majority of the universities aim to have significant impact on reducing scope 3 emissions, but there are challenges such as access to data, reliability of data and standard methodology for calculations. Universities are first focusing on improving their data management practices.

"The absence of a suitable methodology and the difficulty of obtaining meaningful data for huge range of materials procured by the university means that it has not been possible to consider this factor at the present time. The assumptions are used to arrive at the preliminary estimates of the university's scope 3 emissions. Further work is ongoing to refine these estimates using more reliable data." [University of Cambridge Carbon Management Plan, p.17]

Consequently, universities have started to work on scope 3 carbon management with the first step to calculate a carbon emissions baseline. 
"Work is being undertaken to gain a greater understanding of the university's scope 3 emissions. At this stage, quantification of a baseline for scope 3 emissions will be the first target. Subsequently, meaningful reduction targets will be established for scope 3 against the baseline." [University of Birmingham Carbon Management Implementation Plan, p.8]

\section{Carbon reduction targets}

Each of the eighteen universities has set carbon reduction targets in CMPs. Some universities have very ambitious targets, whereas others have relatively less ambitious. CMPs present the universities' carbon reduction targets along the baseline year. These targets indicate organisational commitment towards carbon management in response to the $\mathrm{HE}$ and the national targets. The individual targets of universities contribute towards the overall $\mathrm{HE}$ targets, as the HEFCE targets are the main driver for universities. The HEFCE set carbon reduction targets for 2020 and 2050, but universities have set targets for 2020. This may be because 2050 is simply too far away to make a calculated predicted target. Campuses will change drastically in 30 + years. In addition, some universities have established interim or short term targets to track the progress of the main carbon reduction target.

\section{Types of targets}

There are two types of targets which universities can adopt; absolute and relative. "An absolute target is usually expressed in terms of a reduction over time in a specified quantity of greenhouse gas $(\mathrm{GHG})$ emissions to the atmosphere, the unit typically being tonnes of $\mathrm{CO}_{2}$ e. An intensity target is usually expressed as a reduction in the ratio of GHG emissions relative to another business metric" (WRI and WBCSD 2004, p.77). For relative targets, the most common indicators are per meter square floor area (Per $\mathrm{m}^{2}$ area), per Full Time Equivalent (FTE) student and per unit turnover and emissions are expressed as carbon dioxide equivalent $\left(\mathrm{CO}_{2} \mathrm{e}\right)$. The issue of absolute and relative (intensity-based) targets emerged while analysing the CMPs, however, the distinction between the two types is not very clear. Universities might mean absolute targets in the plans unless it is mentioned relative against a certain indicator. The majority of the universities (eleven out of the eighteen) have absolute targets. Two universities have set both absolute and relative targets, possibly for different reporting purposes, i.e., internal and external. The University of Derby has $27 \%$ absolute carbon reduction target by 2020 from a 2005 baseline.

"The targets to be reported to HEFCE are absolute carbon reductions and do not reflect the dynamic nature of the business and estate. We have therefore applied our own normalised targets against FTE staff and students and in the case of vehicle fleet emissions against mileage." [University of Derby Carbon Management Plan, p.3]

Three universities have mentioned relative targets in their CMPs. These are research based universities having higher energy consumption. The University of Birmingham states that relative emissions are reduced despite energy intensive research. This indicates that relative reduction targets allow business growth.

"As a research led university, a significant proportion of the energy consumed is for energy intensive applications. Despite this, there has been a significant reduction in carbon emissions when compared to growth (financially and in terms of staff/student numbers)." [University of Birmingham Carbon Management Implementation Plan, p. 5] 
De Montfort University's CMP has set the same target as that of the HE sector for scope 1 and 2, which is $43 \%$ carbon reduction by 2020 based on 2005/06 baseline (HEFCE 2010b). This is the only university that has developed the target with two interim targets $(12 \%$ by 2012 and $29 \%$ by 2017). The CMP of the Nottingham Trent University states that the targets are minimum figures, but the university aims to exceed.

"Objective and target figures are to be regarded as bare minimums and as such it will be anticipated that these figures will be exceeded." [The Nottingham Trent University Carbon Management Plan, p. 12]

Robinson et al. (2015) suggest that interim carbon reduction targets should be included as one of the HEFCE requirements allowing universities to identify future challenges in meeting the target through early action. The content analysis found that presently, universities have only set targets for scope 1 and 2 carbon emissions and do not have them for scope 3 . The University of Lincoln's CMP and the University of Bradford's Ecoversity - One Planet Strategy have targets of $43 \%$ and $50 \%$ (scope 1 and 2) by the year 2020 respectively. This indicates universities' commitment towards implementing carbon management.

\section{Carbon emissions baseline}

Carbon emissions baseline indicates a fixed base year against which carbon management performance is benchmarked. Universities have used the methodology and conversion factors taken from the DEFRA and the Department of Energy and Climate Change (DECC) guidance to calculate carbon emissions. Carbon emissions are usually calculated based on an academic year (1st August - 31st July). The majority of the universities (eleven out of the eighteen) have set the baseline of 2005-06 academic year for their calculations and targets, which aligns with the guidelines of the HEFCE. As many universities in the HE sector do not have complete or accurate data for 1990, so HEFCE decided to use 2005-06 as an alternative emissions baseline.

"The institution's carbon emissions baseline has been calculated using data from 2005/6 academic year (1st August 2005 to 31st July 2006). This year has been chosen as it is the earliest year for which reliable and complete data is readily accessible, and is the year that HEFCE is using for the HE sector emissions baseline. The university's financial year also runs concurrently with the academic year from 1st August to 31st July so resource implications and financial savings will be reported concurrently." [The University of Northampton Carbon Management Plan, p.11]

\section{Stakeholder engagement}

Stakeholder engagement emerged as one of the key themes in CMPs. Half of the CMPs (nine) mentioned the role of stakeholder engagement in the effective delivery of CMPs. Universities seem to be focusing on stakeholder engagement that allows coordination for maximum impact of strategies, but there is a lot more work that needs to be done. CMPs do not explicitly identify stakeholders relevant to carbon management process and do not present strategies to engage them. The University of Lincoln defined 'stakeholders' in relation to carbon management as below:

"Stakeholders are those parties either within or external to the university who will be affected by the programme to reduce carbon emissions and may influence its success." [University of Lincoln Carbon Management Plan, p.28]

The universities discussing stakeholder engagement have an agreement that carbon management needs engagement and response at all levels of the organisation. The University 
of Nottingham emphasises the organisation wide stakeholder engagement, but it seems that it is not there yet in many universities.

"The plan requires engagement at all levels of the university from individual behavioural changes to institution led initiatives in order that the objectives are understood and that contributions are made to maximise delivery of the targets. We want to foster a 'can do' approach and response across the university." [The University of Nottingham Carbon Management Plan, p.2]

\section{Staff and student engagement}

Among the university stakeholders, staff and students is the largest stakeholder group and has received more focus in the CMPs. Universities are attempting to engage staff and students with appropriate engagement strategies. Due to this, the majority of the universities (ten out of the eighteen) have clearly elaborated staff and student awareness and engagement activities in their CMPs.

"The university has an objective to increase energy awareness in staff and students." [University of Leicester Strategy and Implementation Plan, p. 11]

Loughborough University's CMP states that every member of university staff and student needs to get engaged for successful carbon management and achieve the targets set out in the CMP.

"If the university is serious about meeting the challenge of achieving the targets set out within this plan and be seen as a leading low carbon campus within the Higher Education sector, every member of staff and the student body needs to engage in the carbon agenda." [Loughborough University Carbon Management Plan, p. 3]

Queen's University Belfast argues that successful implementation of the CMP requires engagement of staff and students rather than only focusing on technical approaches to carbon management. This indicates that staff and student engagement needs to be coupled with technical interventions for effective implementation of carbon management.

"The successful implementation of the CMP, which builds on the mobilisation of the whole organisation, rather than focusing on a strictly technical approach to carbon saving, requires the commitment of all staff and students." [Queen's University Belfast Carbon Management Plan, p.4]

The above quotation indicates the key role of engagement. Universities are implementing projects around change management, awareness raising and behavioural change for staff and student engagement. One of the universities' CMP explains that increasing staff and student awareness and training programmes have proved to be effective across the university. Staff training and education programmes do not seem to be fully developed in the majority of universities. With regards to knowledge and understanding, the majority of staff and students might not understand major parts of CMP due to its complexity and technical terminologies. CMPs are very technical and difficult to understand for ordinary staff and students who do not have experience or education in this subject area. This is one of the major barriers to cultural change in universities. The following quotation reflects the Queen's University Belfast's plans of dealing with human factors.

"A comprehensive awareness raising and educational programme will continue to be developed to help staff and students understand carbon management and its impact on the university." [Queen's University Belfast Carbon Management Plan, p.5] 
The focus of stakeholder engagement is more on staff and students and senior management engagement is overlooked, who are part of senior management team and are involved in strategic decision-making. Mainly lower and middle tier staff is focussed for engagement activities that may not have much influence to bring change in the university. Some of the CMPs provide a 'forward' or statement from a senior executive or VC, but that does not mean they are fully engaged in the carbon management process. CMPs do not clearly discuss how universities plan to engage senior management. Moreover, one university is planning to engage cleaning, security and HR department for carbon management. This indicates the role of every department in the process. Another university recognises the increasing role of student unions in its CMP. Student unions could play their part in engaging student body in an effective way, but there is a lack of active participation.

\section{Funding and resources}

This theme explores the role of funding and resources to implement CMPs because energy and carbon reduction projects require significant financial investment. Universities have established a number of funding mechanisms for projects in CMPs. Seventeen universities' CMPs include the availability of funding to implement the projects. Each of the seventeen universities uses funding from different sources available. Universities seem to be allocating funding as much as they can to ensure that carbon reduction measures are implemented and targets are met, as set out in CMPs. Loughborough University quotes that significant capital investment is required for carbon management.

"Significant capital investment will be required to both assess the feasibility and implement major infrastructure projects that will deliver significant carbon benefits. A full review of the grants and financial support that are available at both local and national level should be undertaken periodically to ensure the university maximises the funding opportunities that are available." [Loughborough University Carbon Management Plan, p.7]

The above quotation indicates that universities explore multiple funding options to maximise opportunities because one source of funding may not be enough to implement the planned projects. Therefore, universities seem to constantly look for more funding options due to issues around funding. De Montfort University shows its commitment of financial investment:

"The university is committed to investing in new technology to achieve reductions in carbon emissions. This investment will encompass energy efficiency, better design and where possible, renewable technologies." [De Montfort University Carbon Management Plan, p.13]

\section{Sources of funding}

Universities have various funding sources available to them. The majority of the universities (eleven out of the eighteen) mention the joint HEFCE and Salix Revolving Green Fund (RGF) for the projects. Salix Finance Ltd helps accelerate public sector organisations investment in energy and carbon reduction projects through 'invest to save' mechanism. The principle of the RGF is that the financial savings generated from interest free loans for energy and carbon reduction projects are recycled back to the central fund for re-investment in other projects. The RGF has two strands; Transformational Fund and Institutional Small Projects Fund. The transformational fund aims to tackle large scale projects in the range of $£ 1-4$ million per institution, which will transform the university's approach to manage energy consumption and reduce carbon emissions (HEFCE 2008c). Four universities have 
implemented large projects through the transformational fund. The other seven universities used funding through the institutional small projects fund, which is a ring-fenced budget for smaller projects. Four universities are using the 'Long Term Maintenance Programme' budget mainly for energy conservation work in buildings. Three universities have set their budget from the 'Capital Funding Programme'.

Two universities have planned to use 'Renovation and Redevelopment' budgets for redevelopment and carbon reduction. Projects funded from these budgets can serve the dual purpose of energy efficient renovation and redevelopment. Three universities mentioned the possibility of external grants and additional resources. There are different organisations and agencies that can further support carbon reduction projects. Two universities have mentioned in CMPs that there is potential for the suitability of the Energy Performance Contracts (EPCs) in their universities under which the EPC provider offers a financial vehicle to implement energy and carbon reduction projects. None of the universities has implemented EPC model, but universities can adopt this model in future. EPCs aim to address financial, technical and procurement related issues and help minimise risks. In addition, CMPs do not discuss the costing procedures for the proposed projects and only one university mentioned it. Each project costs in terms of the capital expenditure (Capex) required and the operating expenditure (Opex) and it needs a life-cycle perspective. Currently, most of the universities do not seem to have ring-fenced carbon and energy related internal budgets. Four universities plan to adopt the strategy of fixed budgets and re-invest savings into future initiatives.

"Establish a carbon management fund pot into which monetary savings from previous carbon management projects can be placed and then used to fund future carbon management projects." [Nottingham Trent University Strategy and Implementation Plan, p.41]

CMPs do not discuss whether previous investments in projects have met anticipated carbon and cost savings in business cases. The University of Leicester states that there is a tendency to 'cherry pick' projects based on shorter payback period and it is not the right approach. The university states that 'Quick Win Projects' have lesser payback period and are a top priority. The 'Long Term projects' require higher investment and have longer payback period and universities tend to avoid that. This suggests that implementing carbon reduction projects have a low priority as far as financial investment is concerned.

“The 'Quick Win projects' are those that have lesser payback period. These projects are of top priority to the university as they are quick energy and cost savers and contribute to the reduction of carbon emissions. The university has financial threshold. The 'Long Term projects' require a higher investment and result in longer payback period." [University of Leicester Strategy and Implementation Plan, p.29]

\section{Governance}

Governance refers to all the processes by which policies and strategic decisions are made (Renz 2007). The governance of a university typically involves the strategic management and decision-making at a senior management level. In this study, governance refers to the processes by which decisions and carbon management strategies are implemented from operational management perspective. It aims to manage a diverse range of elements such as responsibility and communication in the carbon management process. Eleven universities specifically mentioned the term 'governance in their CMPs. These universities have discussed issues around governance for the successful implementation of CMPs and meeting the carbon reduction targets. At an operational management level, governance for 
implementing carbon management strategies starts with the monitoring of energy and fuel consumption and then calculate carbon footprint of the university. Governance can also help develop organisation-wide ownership of carbon management. Loughborough University's CMP states the role of governance in the carbon management programme:

"In order to ensure that there is effective and on-going ownership of the carbon management programme, it is important to define a governance or accountability structure for the programme." [Loughborough University Carbon Management Plan, p.40]

The University of Northampton states that governance of the CMP rests with senior managers in the executive board. The main idea is to oversee and lead carbon management from top and achieve a top-down approach in the university. This could facilitate embedding carbon management in whole organisation. In the University of Northampton, governance and strategic ownership resides with the 'Carbon Management Programme Board' with senior members such as the Pro Vice Chancellor (Strategic Planning and Resources), Director of Estates, Director of Finance and Dean of the School of Science and Technology. This indicates senior level involvement in governance.

"Governance of the programme as well as the strategic ownership of the university's carbon reduction target, rest with the Programme Board, composed of the University's Pro Vice Chancellor (Strategic Planning \& Resources), Director of Estates, Director of Finance and Dean of the School of Science and Technology." [The University of Northampton Carbon Management Plan, p.6]

\section{Responsibility}

Responsibility is an important element for carbon management governance. The majority of the universities (seventeen out of the eighteen) discuss responsibility in CMPs. The content analysis found that responsibility varies in universities and different individuals with different job roles are responsible for carbon management. However, it can be divided into three main categories; middle managers, working/task/steering groups and everyone within a university. The majority of the universities' CMPs (ten) indicate that the overall responsibility lies with a working/steering/task group in universities and four of the CMPs state that 'everyone' is responsible for carbon management. The universities assign operational responsibility to implement carbon management plan and strategies to middle managers based in estates management department. However, the middle managers argue that 'everyone' within a university should be responsible for it, although it is in their job description. Four CMPs state that everyone in the university, all staff and students, are responsible for carbon management.

"Carbon emissions at De Montfort University need to be seen as the responsibility of the whole university rather than specific and individual departments." [De Montfort University Carbon Management Plan, p.13]

The working or steering group generally consists of members from different university departments and faculties such as estates, academics, professional services, senior management and others and is mostly chaired by a senior manager or a member of senior management team. These groups are developed to introduce organisation wide responsibility for carbon management. For example;

"The development and delivery of the Climate Action Plan is supervised by the Sustainability and Environment Advisory Group (Operations)." [The University of Edinburgh Climate Action Plan, p.8] 
Seven universities discuss strategic responsibility in CMPs and it varies from university to university depending upon the organisational structure. Strategic responsibility means strategic oversight by a senior manager, probably a member of the senior management team. Four CMPs mention that Director of Estates has strategic responsibility for carbon management and two of the plans state that it rests with a working or task group of various internal stakeholders. However, only one CMP, the University of Cambridge, states that the Pro Vice-Chancellor (PVC) has strategic responsibility for overseeing carbon management process. This is the only university where PVC is championing carbon management. This is not the case in majority of the universities. The senior management level responsibility could help bring carbon management at strategic level and provide support for resource allocation.

"The Pro-Vice-Chancellor for Institutional Affairs has specific responsibility for carbon reduction and sustainability." [University of Cambridge Carbon Management Plan, p.24]

Members of senior management team are not fully involved in the process despite their official responsibility, apart from being part of the environmental or carbon management group. Strategic responsibility has not received much attention in the CMPs and there is no evidence of wider responsibility at a VC/PVC level. This suggests a gap between operational (middle) and strategic (senior) managers in universities.

"Strategic carbon management is the responsibility of the Director of Estates and Commercial Facilities. Day-to-day operational carbon management responsibility lies with the Carbon Reduction Manager (a full-time post created in September 2010). " [University of Lincoln Carbon Management Plan, p.23]

There is a lack of clarity on the divide between operational and strategic responsibility. Five CMPs mentioned operational responsibility for implementing carbon management. The content analysis found that middle managers are responsible for implementation. Three of the CMPs state that middle managers have operational responsibility, whereas two CMPs state that the operational responsibility lies collectively with a carbon management team or group consisting of middle managers in estates. The middle managers include the sustainability manager, environmental manager, energy manager or carbon manager. This is a full time position in majority of the universities and is based in estates or facilities management department. The CMPs reflect that middle managers seem to be more concerned and relevant to carbon emissions and its management by developing targets. This indicates less involvement of senior management in implementation. CMPs are developed by middle managers and approved by senior management team. Leeds Beckett University quotes on the operational responsibility:

"The Sustainability Manager will be responsible for developing and implementing the carbon management strategy and producing interim reports." [Leeds Beckett University Carbon Management Strategy, p.6]

\section{Communication}

Communication is key for effective governance in universities. Communication is also a key performance indicator in the 'Carbon Management Matrix', which is used to evaluate carbon management performance. Fifteen out of the eighteen universities mentioned communication as a governance issue for implementing carbon management strategies. The content analysis indicates that communication is related to various aspects of carbon management ranging from communicating energy and emissions data, carbon management targets and strategies and novel energy and carbon reduction initiatives to the relevant stakeholders. Most of the universities aim for effective communication practices in their CMPs. There are two types of 
communication; internal and external. Universities are focused on internal communication for engagement with stakeholders, mainly staff and students.

"Regular and relevant communications to support a transition to a low carbon culture across the university will continue." [University of Lincoln Carbon Management Plan, p.8]

An effective communication strategy can help raise awareness and change behaviour of different stakeholders across the organisation, which may contribute in meeting carbon reduction targets.

"A key element of ensuring that the carbon reduction target is achieved is through delivering a successful communications strategy to help implement behavioural change across all aspects of the university's activities." [University of Birmingham Carbon Management Implementation Plan, p.31]

Three universities have separate 'communication strategies' for carbon management. A communication strategy is developed to ensure that all key stakeholder groups are participating and co-ordinating in delivering the CMP. As far as means of communication are concerned, each of the fifteen universities uses different channels to communicate their carbon management message. The most commonly used methods for communication are websites, magazines/newsletters, university reports, awareness raising/behaviour change campaigns, workshops, environmental champions' network, information screens/digital displays, staff trainings and inductions. However, the use of social media has not received much attention in CMPs. Four universities are carrying out employee inductions to inform new employees about the environmental goals of universities. The Strategy and Implementation Plan of the Nottingham Trent University has integrated energy and environmental management good practices in induction.

"All new staff to have energy and environmental good practice inductions along with traditional fire and health and safety inductions etc. in order to instil energy and environmental awareness." [Nottingham Trent University Strategy and Implementation Plan, p.41]

\section{Evaluation and reporting}

Evaluation and reporting of carbon management performance emerged as a main theme. Monitoring the on-going progress of carbon management and reporting is part of the planning process. This can help explore how carbon management is progressing over a period of time and how it can be improved. Almost all of the universities' (seventeen) CMPs discuss evaluation and reporting in relation to their carbon reduction targets and planned projects. Universities intend to evaluate and report through different channels. There could be a problem due to lack of transparency and traceability and CMPs do not reflect on it. There is a vast array of regulatory and voluntary reporting mechanisms available to universities. The University of East Anglia's Carbon Reduction Plan states the role of review and evaluation process:

"To ensure continued reduction in emissions is maintained, it is essential that the programme, projects and the carbon reduction plan are regularly reviewed." [University of East Anglia Carbon Reduction Plan, p.33]

The University of Nottingham plans to develop an annual report to monitor and report the progress and provide an update on the targets. 
"An annual report will be produced to monitor and report on our progress and performance achievements against this plan and to provide an update on the $\mathrm{CO}_{2}$ reduction projects that will ensure that the remaining targets and objectives are met." [The University of Nottingham Carbon Management Plan, p.2]

The majority of the universities (thirteen out of the eighteen) have adopted similar internal reporting procedures. Middle managers report progress to senior management group or committee. The senior management group is chaired by a senior manager, who is a member of the senior management team. The senior manager can be a Pro/Deputy Vice Chancellor to ensure high level championing. Then, it will be reported to the university's senior management team and governing council. Cardiff University describes its internal reporting mechanism as:

"The Carbon Management Plan Task and Finish Group are currently developing the $C M P$, which will then report through the Environmental Management Systems (EMS) Steering Group, which is chaired by the Deputy Vice-Chancellor, which will oversee implementation and further development of the plan." [Cardiff University Carbon Management Plan, p.3]

The above quotation highlights reporting, which the majority of universities carry out. At an operational estates level, four CMPs mention that universities have adopted a series of Key Performance Indicators (KPIs) to monitor and report the performance. The KPIs include $\mathrm{CO}_{2} \mathrm{e}$ emissions, $\mathrm{CO}_{2} \mathrm{e}$ emissions per £million turnover or Full Time Equivalent (FTE) staff member and students.

"Carbon reduction is incorporated as a KPI at both institutional and School/Directorate level, with progress in meeting targets included in all School and Directorate Annual Performance Reviews submitted to the University Operating Board in November each year. These are, in turn, reported to the University Management Board, the Planning and Finance Committee and, ultimately, to Senate in December." [Queen's University Belfast Carbon Management Plan, p.6]

Different universities have different timescales for reporting. Half of the universities report progress annually, both internally and externally. The focus is on internal reporting within the CMPs to gain senior management support. The universities report externally through mandatory and optional policies and schemes in the UK. HEFCE demands that universities measure and report progress against sector-level targets. The University of Northampton defines its objectives with regards to implementation, review and update:

"The university recognises carbon management as a strategic, whole-organisation approach that integrates with our existing strategy and management, enabling the institution to understand the impact of carbon emissions, to identify key risks and opportunities, to formulate a plan to reduce carbon emissions, to effectively implement, review and update the plan into the future, and to communicate success." [The University of Northampton Carbon Management Plan, p.7]

\section{Discussion}

This paper presents the analysis of eighteen universities' CMPs to explore carbon management planning in UK universities and identify key elements as part of their journey to a low carbon built environment. The paper speaks to contemporary policy concerns around climate change and carbon management in the context of the HE sector. The novelty of the analysis advances our understanding of carbon management area both theoretically and practically by offering insights into how universities are planning carbon management and 
what are the areas of improvement. Our study found that almost all of the universities have CMPs and are starting to understand the strategic role of carbon management. The CMPs studied were quite similar in design, which suggests consistency. CMPs are a valuable tool that has the potential to place universities on the pathway of implementing carbon management. This finding corresponds with Robinson et al. (2015), who argue that CMPs have helped the sector take carbon emissions seriously. Despite these positive findings, there are concerns. CMPs are overly focused on operational issues rather than strategic. Technical details and projects are dominant whilst there is little emphasis on non-technical or human factors. This might be because CMPs are designed by environmental and technical managers in estates department. This makes CMPs complex and less effective in communication with stakeholders. CMPs do not seem to be integrated into other university policies and strategies; rather they are a stand-alone document. CMPs face challenges such as future uncertainty and changes. Sometimes, it is difficult to predict the future scenario while developing a CMP. For example, increase in student numbers, weather conditions, policy changes and technological advancement. It is difficult to identify projects, as situation may change, for example changes in the HE sector may influence it. Altan (2010) and Lee (2012) state that business growth and expansion of estate are the major challenges for carbon management in universities.

The majority of the universities measured carbon emissions from scope 1, scope 2 and selected parts of scope 3 and have developed plans and strategies. Universities are now in the implementation phase of CMPs. Universities have shown commitment to reduce emissions and have targets to support the HEFCE and national targets. All of the sample universities have set targets, but CMPs do not reflect whether they have achieved actual reductions over a period of time as there is no sector study. However, setting high targets and not making a realistic effort to achieve them should be perceived as 'green wash'. There is no accountability from HEFCE since the change in funding mechanism in the HE sector. Robinson et al. (2015) argued that having unachievable targets can be harmful as middle managers may lose interest and support of senior management leadership. Ambitious targets are less likely to be achieved and the problem is that realistic but relatively low targets can be criticised and penalised in league tables, such as the People and Planet University League. The majority of the universities have plans to meet absolute targets, which could be difficult due to energy intensive activities and business growth. This corresponds with Lee (2012) who argues that energy intensive research along with growing estates is counter-productive to carbon management. In contrast, universities have relative targets for reporting and allowing business growth. It might be interesting to quantify if universities are successful in meeting absolute targets. The national and HE targets are absolute for scope 1 and 2; although some selected parts of scope 3 are measured by many universities. However, mostly universities are lagging behind in dealing with the measurement, targeting and management of scope 3 . It might be because scope 3 is not mandatory and HEFCE has advised to develop targets for scope 1 and 2 (HEFCE 2010b). Universities do not have the data for all scope 3 streams for carbon footprinting, but they understand the important role of indirect scope 3 emissions; especially procurement and travel.

All of the CMPs are signed by a VC or any other senior manager, but their role is limited in the process. Senior leaders not only need to have a vision, but they need to ensure the implementation of the vision (Millar et al. 2012). Our analysis suggests that strategic and operational aspects of carbon management are not joined up. Although many universities have planned to adopt whole-organisation approach, this might not be there yet and need a strategic approach (Schultz and Williamson 2005). The whole organisation approach constitutes students and staff in all faculties and directorates, both academic and professional services engaged in reducing emissions from the direct and indirect sources (scope 1, 2, and 
3). In contrast, carbon management has started to emerge at the strategic agenda albeit slowly and CMPs could play a significant role in implementation. Funding and resources is an important part of implementing carbon management strategies. CMPs suggest that there are different funding options available to implement projects and universities are using multiple sources. Some of the projects have got required funding and some are subjected to further funding approval. Some projects do not even get implemented due to lack of funding in universities. Therefore, funding is considered crucial element for the implementation. Universities have competing demands in the current financial climate and may need innovative funding models for carbon management. Stakeholder engagement is a key factor and aims to bring internal and external stakeholders together. Universities are focused on staff and student engagement and the engagement of senior management is not addressed in CMPs. Many universities have not been able to make CMPs an interactive tool to engage stakeholders due to complexity. CMPs fail to make staff, students and other stakeholders understand what it means to them and how can they contribute to it. CMPs are not visible in universities. Universities seem to have embedded statements into CMPs rather than providing solutions to problems or their causes.

There is a wide range of job titles for individuals responsible for carbon management. However, responsibility varies based on structure of the organisation and seems to be unclear. This matches with the findings of Chen (2011) who state that responsibility of addressing climate change varies largely ranging from the presidents of universities to environmental or sustainability coordinators. The overall responsibility varies and mainly rests with working or task groups consisting of individuals from different university departments. The operational day-to-day responsibility lies with middle managers in estates, whereas strategic responsibility is with senior manager or director of estates who oversight the process. Carbon management is seen as a responsibility of a specific department and/or individual in universities. Predominantly, carbon management is implemented by environmental team in estates department, whereas other departments have no or very little contribution. This suggests that there is a lack of responsibility and management is disjointed and lacking in coherence and coordination. Middle managers do not have authority and involvement in strategic decision-making and they need approval for most of the projects either from the director or senior management team.

Universities review, evaluate and report performance on regular basis through different forums. Updating CMPs and tracking the progress against targets is part of it. This could help managers understand where they are and where they want to go in future to meet the targets. The review and evaluation offers lessons to be learnt for future. There is a lack of consistency and complexity in existing methods for measuring, targeting and reporting within HE and they are all different. Although there are common external reporting mechanisms, but internal reporting varies. The reporting system could be standardised to compare universities. Internal reporting system is emphasised in the CMPs for internal stakeholders. There are legislative and policy drivers for carbon reporting such as Carbon Reduction Commitment Energy Efficiency Scheme (CRC EES). By reporting emissions, universities can improve performance against a benchmark and review CMPs for improvements. The fact that many universities have not updated their CMPs suggests that the plans are static and not all universities are fully committed. This indicates slow progress or managers being busy due to other priorities. This could indicate that universities are drifted away from CMPs since the change in HEFCE policies due to lack of accountability and the plans are out of date (see Table 1). Brite Green (2015) found that many HEFCE funded universities need to revise their CMPs to meet 2020 targets. 


\section{Conclusion}

Carbon management is a crucial issue that needs effective planning and implementation in universities if the ambitious carbon reduction targets are to be met. In the UK, most universities have developed CMPs as part of policy compliance and are now in the implementation stage. However, there is a long way to go if the CMPs are going to enable universities to reach their full potential. UK universities took a lead by setting carbon reduction targets and developing CMPs. HEFCE's work in the area carbon management is innovative and offers lessons to be learnt. Other universities and organisations can learn from the planning experience and knowledge of the UK universities. This study has identified the key elements of the carbon management planning process and universities need to focus in those areas for successful carbon management to meet carbon reduction targets. Despite various advantages of CMPs, there are potential areas of improvements which this study has highlighted. This study will be useful to academics and practitioners aiming to improve carbon management planning in universities and other organisations nationally and internationally. Of course there are limitations to this study. The authors depended on the analysis of official university documentation and it is acknowledged that the limitation of using such sources of evidence as what is said does not always correspond with what managers think or do in universities. Future research can address this issue by gathering primary data from universities to carry out a comparative analysis. With regards to carbon management planning, future research will also be necessary to develop a better understanding of how successfully CMPs are implemented against the set targets.

\section{References}

Altan H (2010) Energy efficiency interventions in UK higher education institutions. Energy Policy, 38 (12), 7722-7731.

Busch T, Shrivastava P (2011) The Global Carbon Crisis: Emerging Carbon Constraints and Strategic Management Options Greenleaf Publishing, Sheffield, UK.

Bebbington J, Barter N (2011) Strategic responses to global climate change: a UK analysis. Chartered Institute of Management Accountants, 7 (11), pp. 1-10.

Ball A, Mason I, Grubnic S, Hughes P (2009) The carbon neutral public sector: early developments and an urgent agenda for research. Public Management Review, 11(5), pp.575600 .

Brite Green (2015) 2020 Carbon Reduction Target: Progress Report of De Montfort University, Brite Green. London, UK.

Chen C (2011) Climate Change Leadership in Higher Education Institutions, Unpublished $\mathrm{PhD}$ thesis, Duke University, USA.

Cadez S, Czerny A (2016) Climate change mitigation strategies in carbon-intensive firms. "Journal of Cleaner Production", 112, pp. 4132-4143.

Carbon Disclosure Project (2010) The carbon management strategic priority: Carbon Disclosure Project (CDP), London, UK.

Davies JC, Dunk RM (2015) Flying along the supply chain: accounting for emissions from student air travel in the higher education sector. Carbon Management, 6(5-6), pp.233-246.

Her Majesty's Stationery Office (2008) Climate Change Act 2008 Her Majesty's Stationery Office (HMSO), London, UK. 
HEFCE (2008) The 2008 grant letter and key performance target measures relating to carbon emissions: Report to the Secretary of State for Innovation, Universities and Skills, HEFCE, Bristol, England.

HEFCE (2010a) Carbon management strategies and plans: A guide to good practice, HEFCE, Bristol, England.

HEFCE (2010b) Carbon reduction target and strategy for higher education in England, Bristol, England.

Higher Education Statistics Agency (HESA) (2014) HE Statistics for the UK 2012/13. Available at: https://www.hesa.ac.uk/pr/3226-press-release-208 (Last Accessed 31 January 2015)

Hoffman AJ (2007) Carbon strategies: How leading companies are reducing their climate change footprint: University of Michigan Press, USA.

Kolk A, Pinkse J (2004) Market strategies for climate change. European Management Journal, 22 (3), pp. 304-314.

Klein-Banai C, Theis, TL (2013) Quantitative analysis of factors affecting greenhouse gas emissions at institutions of higher education. Journal of Cleaner Production, 48, pp. 29-38.

Lee SY (2012) Corporate Carbon Strategies in Responding to Climate Change. Business Strategy and the Environment, 21(1), 33-48.

Millar C, Hind P, Magala S (2012) Sustainability and the need for change: organisational change and transformational vision. Journal of Organizational Change Management, 25 (4), 489-500.

Mazhar MU, Bull, R, Lemon M, Mallaburn P (2014) The current state of strategic carbon management within the UK higher education sector: leading the way forward?. In: Proceedings of the 9th International Symposium on Sustainable Leadership, 3-6 June 2014, Salzburg, Austria, pp. 148-160.

Mazhar MU, Bull R, Lemon M (2012) A review and case study of strategic carbon management in UK Higher Education sector, Proceedings of Royal Institution of Chartered Surveyors (RICS) COBRA Conference, September 2012, Las Vegas, Nevada, USA.

Robinson OJ, Tewkesbury A, Kemp S, Williams ID (2017) Towards a universal carbon footprint standard: A case study of carbon management at universities. Journal of Cleaner Production, http://dx.doi.org/10.1016/j.jclepro.2017.02.147

Robinson O, Kemp S, Willaims I (2015) Carbon management at universities: a reality check. Journal of Cleaner Production, 106, 109-118.

Renz DO (2007) Non-profit Governance and the Work of the Board. University of Missouri, Kansas City, USA.

Stern N (2006) Stern Review: The Economic of Climate Change. Stern Review Report, UK.

Schultz K, Williamson P (2005) Gaining Competitive Advantage in a Carbon-constrained World: Strategies for European Business. European Management Journal, 23 (4), pp. 383391.

The Carbon Trust (2012) Public sector most committed to carbon reduction. Available at: https://www.carbontrust.com/about-us/press/2012/02/public-sector-most-committed-tocarbon-reduction/ (Last Accessed 10 April 2013) 
The Carbon Trust (2013) How the British public sector is leading the world on climate change action. The Carbon Trust, London, UK. Available at: http://www.carbontrust.com/news/2013/11/british-public-sector-leading-world-on-climatechange-action (Last Accessed 14 December 2013)

Wittneben B, Okereke C, Banerjee B, Levy D (2009) Climate change and the emergence of new organizational landscapes. Organization Studies, 30(9), pp.1013-1015.

Weinhofer G, Hoffman VH (2010) Mitigating climate change-how do corporate strategies differ?. Business Strategy and the Environment, 19 (2), pp. 77-89.

Wehrmeyer W, Leitner A, Woodman P (2009) Lean and Green: Leadership for a low-carbon future: Chartered Management Institute, London, UK.

WRI, WBCSD (2004) The Greenhouse Gas Protocol: A Corporate Accounting and Reporting Standard (revised edition): The Greenhouse gas Protocol Initiative, USA and Switzerland. 